\title{
Rituals in E-Government Implementation: An Analysis of Failure
}

\author{
Rahul De' and Sandeep Sarkar \\ Indian Institute of Management Bangalore \\ $\{$ rahul, sandeeps08\}@iimb. ernet.in
}

\begin{abstract}
This paper presents a case analysis of a failed e-government implementation in a developing country context. The project involved constructing a large system for a central government department in India. After seven years and a few million rupees in costs, the project was terminated. Prior research in failed information systems implementations has highlighted many issues, most of which are now part of software project management literature. With e-government systems, though scientific project management is diligently applied, failure rates are very high, particularly in developing countries. The analysis in this paper suggests that though issues of lack of user involvement, inadequate delegation, and improper planning are responsible, the important causes are the rituals that management enacted, that had overt rationality but buried agendas.
\end{abstract}

Keywords: e-Government, system implementation, failure, developing country, India.

\section{Introduction}

E-government systems constitute a priority for many governments of developing countries as a means to reform and modernise governance. This priority has ingrained into policy and led to massive allocation of funds for computerisation. Government departments take pride in their computerisation efforts, and their ability to stay 'ahead' of their manual-only counterparts. E-government is built for two kinds of situations - those that are internal to departments and those that are public-facing to provide some service for citizens at large. The effort to computerise, in a developing country like India, has included both types of systems.

This effort, though, comes at a price: many projects fail and constitute a waste of money and personnel time. Some researchers report that the failure rates in developing countries are quite high, to the extent of more than $80 \%$ of projects being total or partial failures [89. It is thus important to understand why projects fail and what measures can be taken to eliminate or reduce such failures.

This paper examines a failed e-government project in India. The project was intended to build a financial management system for a large government department of the central government of India. The project lasted about seven years, from initiation to its final closure. 
On the surface, the project appears to reflect the classic problems of project failures anywhere - top-down push without much stakeholder buy-in; conflicting and un-clear goals; inadequate risk assessment and contingency planning; unclear delegation; and poor vendor management. However, a deeper analysis reveals that there are strong issues emanating from the culture and practices of government departments of developing countries and the project management failures are but a symptom of the deeper issues.

This paper proceeds as follows: the following section reviews the literature in egovernment in developing countries and also the Information Systems literature on project implementation failures. The main research question is identified, and the methodology followed in this research is discussed. This is followed by a description of the case data after which an analysis is presented. The paper concludes with a discussion of issues in failed e-government projects.

\section{Background and Literature Review}

E-government in developing countries started with the computerisation efforts for building applications within departments, or e-government systems, that were implemented with the direct assistance of developed nations or multi-lateral funding agencies. These efforts date back to the $60 \mathrm{~s}$ and $70 \mathrm{~s}$, and were few and restricted to well-known data crunching operations such as the census or tax processing. The emphasis on public facing systems grew with the advent of the public Internet in the 90 s and the spread of connectivity across developing countries.

Research in e-government systems in developing countries has mainly focussed on identifying successful projects that can be replicated [11, or on evaluation of such systems to see if they are indeed realising the intended impacts (or understand what the impacts are) [12[14[15]. There are few papers that closely examine failures, to understand what went wrong and why, and what lessons can be learned. This paper addresses such a gap in the literature.

Failures in information systems implementation is an area of study that has received much attention 6/7/10. The research in these papers sought to explain failures, and consequently point to how success could be achieved. Large system implementations were deeply complex and required planning of every possible detail. This was treated in a technical project planning manner, with the evolution of the field of software engineering and software project management. However, despite the detailed planning, systems implementations still failed and this led to research uncovering issues of politics [13, democracy [5, user participation and conflict 2, and control [3, amongst others.

The research does differentiate between project implementation failure issues during the course of the project, from failures happening after the project is complete and implementation is being undertaken in the organisation. The difference between the two is subtle but important. E-government systems are affected by both kinds of problems. In this paper the focus is on the former.

The nature and priorities of project management issues for e-government projects are different from private sector or profit-seeking firms. The issues have 
to do with the manner in which projects are conceptualised, the manner in which they are funded, the role of various department heads and functional heads, the duration of project managers with the project, and the entrenched problems of power, control and resistance [17].

One issue of particular interest is that of the rituals of project management that some stakeholders enact 16. Rituals are perfunctory duties that employees and stakeholders of the organisations perform in order to satisfy the needs of project management techniques and guides. Rituals take the form of setting targets, team formation, requirements analysis, and so on, however the stakeholders often have no interest in seeing the project through in this manner, and often have alternative, personal agendas.

In theory, rituals in organisations serve to confirm and consolidate organisational practices, or serve to suppress conflict and control [1]. Further, rituals also enable sense-making of social processes 4 .

The bureaucracy in developing countries is often a structure that wields immense power and plays an important role in the implementation of systems. For countries such as India, the bureaucracy is structured as a strict hierarchy, with an elite core of civil servants at the top, supported by cadres of the lower bureaucracy at the state and district levels. The upper bureaucracy retains centralised control over all sanctions of resources [18. Further, they are held on very short tenure at their respective positions, and are invariably rotated at least every three years.

\section{$3 \quad$ Research Question and Methodology}

This paper examines the problem of system implementation failure, but from the context of an e-government system in a developing country. The context of a developing country and e-government system is sufficiently different from the context of similar studies of system implementation failure in private, profitseeking firms. This implicit assumption drives the research question for this paper:

What are the principal causes of system implementation failure in egovernment projects in developing countries? How do factors such as stakeholder goals, power, politics, and rituals enable these causes?

The methodology followed for this paper is that of case study research [19]. This methodology is considered appropriate as the research is exploratory. The study consists of 22 interviews of project staff belonging to a large Indian government department, where an IT implementation was under way. The interviews were of system implementers, project team leaders, user staff, unit heads, vendors, and top management of the department. Each interview lasted for a duration of 30 - 60 minutes. Project documents were sought and collected, wherever possible.

In the following section the case data is presented as an independent narrative, followed by the analysis. This separation enables an independent verification of the analysis. 


\section{The Case Data}

The case concerns the efforts of a department (referred to as the Department), of a large Ministry of the Central Government of India, to implement an information system. This department provides financial services to all the organisations under the administrative control of the Ministry. The functions of the Department involve assimilation and processing of a large volume of data, mostly financial. The Department oversees the fiscal management of a budget of approximately USD 39,260 million (at 2009 prices). As paymasters to approximately 1.7 million personnel located across the country, the Department has to ensure accuracy of payment and audit of the same. Another major task of the department is pension sanction, payment and grievance redressal where it oversees pensionary benefits to approximately 2.2 million retired personnel - an activity that is fraught with political risks. With major capital acquisitions for modernization of the Ministry being a priority, and an emphasis of the government on austerity and prudent financial management, the Department plays an important role.

The Department has a history of automation of its work processes, started in the 1970s. By the mid-1990s, a realisation of technical obsolescence had set in, also arising out of issues of depleting manpower, increased transactions, increased expectations of the clients (who had carried out extensive automation of their own work processes), as also technical problems such as data inter-operability. In 2002 the Department launched an ambitious automation project (henceforth referred to as the Project) aimed at a total online integrated computerisation of all functions. The Project was sanctioned as a major e-Government initiative in 2004 at a total cost of Rs 420 million (USD 9.1 million), to be completed by 2007.

The Project was the brain child of a very senior officer of the Department (called the Charismatic Leader) who, though not occupying the top rung, was influential enough to push for this project. He created a band of followers, mainly officers from the middle management, who would fulfill the development and implementation of this information system project.

Initially, Study Groups were constituted for major functional areas of the Department. These groups, led by a Branch Head and comprising of 3 - 4 officers, looked into the areas currently automated, the weaknesses in them and made suggestions for the future. Since all functions of the Department were proposed to be automated, and there were common areas of work in different offices, the evolved approach was that such common functions would be developed only once in the project. The constitution of the groups was decided by the Charismatic Leader. Based on the recommendations of these study groups - which came in by mid 2003 - unique functionalities of various offices were treated as separate 'systems' to be developed. These were again divided into (a) Main systems which comprised of the core functions of an office and (b) Plug-in systems which consisted of functions common across one or more offices. As the software development was to be outsourced, one or more systems were clubbed into a 
single "Lot" based on common functions. By the third quarter of the 2003-04, the Vision Document - outlining the design and project management techniques - was sent out.

Project Teams - comprising of domain experts and users of the particular function that was to be automated - were created on site, in field offices, and were tasked with aiding the implementation at the respective locations. The overall control and coordination of the project - including issues of software development, hardware procurement, tendering, manpower training and placement - was made the responsibility of another body called the Project Steering Group (PSG) which was located at the Headquarters. The PSG and Project Teams were staffed by a few officers (middle management) handpicked by the Charismatic Leader. There were two visible faces of PSG whom we call the Lawyer and the Engineer. The PSG and the Project Teams drew their authority and mandate from the Charismatic Leader. In fact certain middle level officers - particularly the Lawyer and the Engineer - had direct access to him.

The Project created a lot of enthusiasm and expectation in the Department in the initial stages. A lot of training - from basic computer literacy to advanced Java - was imparted; computer hardware and networking equipment was procured; test data was created and so on. The Project was looked upon by some of the personnel as a means of freeing them from the drudgery of routine financial tasks that their charter of duties entailed. Some of the Project Leads and younger officers got down to delivering the goals set by the Charismatic Leader. Recalled an earlier Project Lead: "This was the first time when we were given the mandate to think to suggest and change procedures, documents and work flow - something which we had so far accepted as a given. We felt that as the inheritors of the department, we owed it to ourselves to set up this automation project and carry it to finality. It would have only helped us in the long run".

After the study group submitted their reports - where they had collected input requirements from the functional heads of the field sites - the policy for managing the project left out the Branch Heads from the major decision areas. Most of the decision rights lay with the Headquarters and in particular with the Charismatic Leader and the PSG. Having decided on the policy, the implementation aspects were left to the middle management officers who were charged to deliver by making them the Project Leads. The Project Teams (in the field) had direct reporting access to the PSG (at the headquarters), who in turn reported (informally) to the head of the Department.

Echoing these issues, a senior (now retired) officer, who headed one of the largest field offices of the Project, said: "The Branch Heads seem to have been left out of the loop in arriving at the system design and the prioritization of the functions that would form a part of the projects applicable to their own offices. The Project Teams used to interact directly with the PSG, take their instructions from them and move onto their implementation. The Branch Head would come to know if the Project Lead chose to inform them or if he took pains to learn so by himself. This did cause alienation amongst the senior officers in 
the field who felt that they were not considered fit to be consulted. The PSG had become all powerful."

Realizing this disconnect the Headquarters in March 2006, fearing a lack of ownership of the project amongst the top officers, solicited their involvement. The same retired officer said: "Yes they did try and involve the Branch Heads, but by that time the basic design, architecture and priority of development had already been developed, contracts with software vendors entered into and there was little scope to make any changes. The realization came a bit too late."

Between September 2003 and mid-2006, the User Requirements and Specifications (URS) were firmed up and written by the Project Teams. Based on the clubbing of Lots, tendering action for software development began and contracts entered into. While the process of sending Requests-for-Proposals began in mid 2004, the first contract was signed in March 2005 and the last one in March 2007.

By the first quarter of 2006, Charismatic Leader had left the Department and moved onto the Ministry, and his direct intervention in the affairs of the Department declined.

After the retirement of the successor of the Charismatic Leader, in mid 2007, the resources that were being committed to the project began to decline. The IT setup in the Headquarters office - of which PSG was a part - began to shrink and officers were posted out, and the posts were never filled. Said the Lawyer: "In the field the early Project Leads who shared the vision of the Project started to move out. In some cases they were replaced by officers who did not own up the project. Though we requested for changes, none took place."

When the successor to the Charismatic Leader retired, while work progressed on some Lots, the ones tendered out initially started experiencing problems. Differences arose between the Project Teams and vendors at the testing stage. The failure of one firm, which had been awarded contracts for four systems, to deliver the project milestones complicated things further as the performance of the first tendered lots were being watched keenly in order to establish benchmarks for the remaining ones. While there appeared to be issues of vendor inefficiencies, voices of dissent over inadequate resources, lack of authority and frequent changes in the composition of Project Teams, began to emerge from the field Branch Heads. Issues of improper planning were raised mainly by the new officers who replaced some of the ones who were moved out of the Project Teams. Realizing that there would be substantial time and cost overruns, the Department - now under a new Department Head - moved the Ministry for an extension. This was granted in September 2007 as a result of which the cost was now pegged at Rs 500 million (USD 10.87 million) and the project was given a new deadline of December 2009.

The Project was seen as highly centralized, with too many decisions taken at the headquarters. The uniformity and standards (in project conceptualization, URS writing, etc) that the Headquarters and PSG had envisaged, as an efficient project development technique, began to be seen as a covert act of centralization. One of the senior Branch Heads went on to say: "This centralization of procedures and processes does not give leeway to design and develop the application as per our needs." 
By the third quarter of 2007, when a new set of officers arrived at the Headquarters the voices, on the viability of the approach towards automation of all functions at one go (as against an incremental development process) and the lack of authority given to field offices and the Project Teams, became shriller. A senior officer, who had been part of one of the original project development teams of the 1980s (called the Pioneer) said: "We should have learnt from our past experience that a big bang approach, as evident in the Project, does not work..."

Many of the respondents indicated that adequate and requisite inputs had not been provided during the design of the project. This had to do with the non-involvement of business/process owners (the 'non IT personnel' as dubbed by most officers) in the initial design. The general feeling that had begun to emerge was that the approach adopted in the Project was esoteric, not-workable and certainly not in tune with the ground realities.

Concerns were also being voiced by some of the Branch Heads over the adverse fallout of the project on their regular functions as the members of the Project Teams were unable to devote more time towards their regular duties due to their preoccupation with the Project. They made no bones about their displeasure on the additional work entrusted to their subordinates. The views of a senior (now retired) field Branch Head: "I have to take care of my bread and butter functions first - I am paid for that. Everything else can wait. I cannot afford to have my officers devote a major portion of their working time to one project and neglect the core functions of the office in the process."

The vendors also started complaining of non-cooperation by the Project Teams. Scope creep and a lack of ownership - manifested primarily in the unavailability of Project team members and a hesitation to sign (on reports etc) - were reported by them. Often the vendors used to take their problems and complaints directly to the PSG who, at Headquarters level, was responsible for management of the contracts. Their intervention to sort out the issues between the vendors and the Project Teams were seen as bullying tactics by the latter and consequently resisted. In their eagerness to push the project and to adhere to the deadlines, the PSGs efforts in this direction were seen as siding with the vendors, by the Project Teams, and resented as acts of unwarranted intrusion into the domain of the latter. An officer who had headed one of the Project Teams earlier said: "Instead of understanding our problems and helping us resolve them, at the behest of PSG we were often hauled up for delaying the project. Headquarters does not have a clue on project management. There is no forum to resolve issues."

One official report, on the problems in the project, also highlights this issue. Opined the Pioneer: "There is a lot of alienation amongst the field officers and especially the Branch Heads. When project problems were reported to the PSG - the body responsible for coordination issues - one usually got an advice to sort out issues at their own end."

When these issues were posed to the Lawyer and the Engineer they pointed out that they had taken pains to understand the problems on the ground by not only studying each URS in detail but had made many trips to most field sites to 
resolve issues and had, in their opinion, made substantial progress. The Engineer was also said: "We never acted as bosses from Headquarters office. We tried to keep all communication channels open and were very open and receptive to the ideas and concerns of the field offices...."

While they did admit that there may have been flaws in the project management plan, the Lawyer and the Engineer were of the opinion that these could have been corrected if the top management had really owned up to it. As an issue that was close to their functional area, they pointed to the hesitation to deploy more manpower to the project and to ensure their permanence - at Headquarters as well as in the field.

Things were difficult in most of the field offices. One official report points out that: "Principles of sound IT Project Management have not been adopted for executing the Project, rather the Project [was] implemented under the normal bureaucratic manner. The (Project Leads) were not given adequate authority to discharge day to day responsibility."

By the end of 2007, the enthusiasm of the early days had been overtaken by a despondency and a tendency to stay away from the project or at best letting it run its own course. A feeling had developed that even after so much effort (and time and money) none of the systems were near completion.

The situation for the Project got worse in 2008. There were immense delays in the project milestones, in all the Lots. None of the original members of the Project Teams, and most of the Branch Heads, to whom references had been made in 2006, were in their respective positions anymore. On top of this, the Central Government in India announced new pay and other entitlement structures for its employees in September 2008. This came as a nail in the coffin for most of the Lots in the project. The basis for calculation of various allowances (pay, pension etc) were radically altered necessitating large scale changes in the software logic. This effectively put a major portion of the project on hold as, irrespective of the stage of the earlier development, the project stages from URS onwards needed to be revisited.

In November 2008, the Department set up a committee to review the project. The committee - comprising primarily of officers who had proposed alternate project management approaches - sought comments and views of all the Branch Heads, whose offices were the declared project development sites. The Lawyer and the Engineer were however not consulted. The committee came to the conclusion that the project was a partial failure and there was a need for closure of some of the Lots. The Department issued termination notices for the four chosen Lots in August 2009.

By this time, the setup in the headquarters IT division of the Department had been changed. Both the Lawyer and the Engineer had been transferred out in the first quarter of 2009 and a new set of officers had come in. Interviews with them revealed that one of the top priorities, at that time, was to short-close most of the contracts and to rethink the automation project. Thus the need to automate to improve service delivery had come a full circle since its inception in 2002. 


\section{Analysis}

The Department is a microcosm of the larger Government and bureaucratic structure in India. It is highly compartmentalized in its functions and has a layered structure. While most of the lower grade personnel are recruited into the clerical grade and then make the slow climb up the hierarchy, the officers, a minority recruited from the Civil Services or promoted from the lower ranks, are generalists but have the largest decision rights in the functioning of their offices. While there is specialization in the lower cadres, the structure is highly formalized and bound by rules and procedures, some dating back to the preIndependence era. The decision making process on major issues is highly centralized.

\subsection{The Overtly Rational}

The case shows a preponderance of behaviours by the leading participants in the project that is described as "overtly rational" by Robey and Markus (1984). These are behaviours and actions taken by the project leaders that were meant to conform to project management procedures. Hindsight shows that these actions could not have achieved what they were supposed to achieve, however well they may have been executed, owing to the particular context of the organisation and its composition.

Project Management Structure: The Charismatic Leader created project teams and the PSG, staffed with the Lawyer and the Engineer, to create a clear and unambiguous decision hierarchy for the project. Tasks were identified and allocated, and the plan for activities, reporting relationships, and responsibilities was laid down. There was enthusiasm for the project and the roles assigned as one project lead stated "... this was the first time when we were given the mandate to think to suggest and change procedures...."

However, the data shows that this structure clearly violated the norms of strict hierarchy, and, in fact, by-passed the Branch Heads altogether although they had the most authority as the users. The reporting relationships in the team enabled those junior to the Branch Heads to report directly to the PSG or to the Charismatic Leader. When it became clear that this short-circuit in the hierarchy was becoming a problem, another overtly rational activity was undertaken - that of including the Branch Heads in the decision making. However, by this time the design had been formalised and fixed, leaving no room for any serious inputs by the Heads.

Project Execution: The project leadership empowered the teams to handle the execution tasks. This was done formally, with a clear delegation of tasks. The execution initially proceeded well, with considerable motivation from the PSG and the team. Vendors were to deliver on the Lots and these were to be tested and verified by the teams. This was the overtly rational behaviour.

The execution of the project was prioritised by the central leadership, with some choices left to the teams. The teams later complained that they "...were not 
given adequate authority to discharge day to day responsibility" while working on the project. Vendors were not managed, and were left to deal with scope creep and lack of ownership on their own. The staff rotation, which was routine and well known, was not accounted for and many staff who left were not replaced.

After the Charismatic Leader and his successor moved on, or retired, the project execution seems to have collapsed almost entirely. The centralised control had snapped and the remaining power structures were not up to the task.

The Worldviews: The Charismatic Leader had envisioned the project with a certain worldview. It was to be conceived and executed on a grand scale, covering a wide swathe of functions and branches of the Department. In 2002, this was not a far fetched idea in India. The Indian IT industry was strong and well known as being highly competent. Much larger projects had been initiated in other government departments, and some had been delivered successfully. So the plan of a "big bang" approach had merit and overt rationality.

In the later stages of the project, the new team of leaders who took over the reins differed with the grand implementation idea, and were of the view that the project would have been better implemented in stages, a tactic the Department had been successful with in the past. This was a worldview and a vision of project management that was in stark contrast with the overt rationality of the Charismatic Leader and his team.

\subsection{Rituals}

Rituals are powerful and central to the Indian ethos. Their practice has the legitimacy and sanction similar to that of religious observance. They are the core of ceremonial behaviour and reflect a rationality that has an inherent, implied logic that is not expressed and is rarely explained. The rituals enacted in the project had a similar tone - though they purported to correspond to a rationality of scientific project management. Teams were formed, designs were made, plans were drawn up with the overt rationality of objective and scientific actions. This is re-affirmed by the official committee that reported principles of scientific management had not been followed and the project was "...implemented under the normal bureaucratic manner."

When the emergent problems challenged the rationality, the response was to re-affirm the plans, and devise further rituals as recompense. Project teams were hauled up when there there slippages in deadlines, without any investigation. The ritual of decentralised control was enacted and teams were told to "... sort out issues at their own end."

These rituals enabled the team at headquarters to retain strong control over all aspects of the project - from initiation, funding, planning, design, to execution. An overt rationality of scientific management masked these rituals and enabled them to be played out without active resistance from other stakeholders 1 . It is important to note that the power play inherent in the rituals was designed to control the implementation process, and legitimate it, thus subverting the possible power inversions that could result after the system was available and in use. 
Rituals uphold values of 'scientific management,' and 'efficiency,' and 'effectiveness' and are endemic in government departments. They mask the underlying power plays and manoeuvrings that are constant and pervasive in all e-government projects. With systems implementations being undertaken at such a large scale in developing countries, it is imperative that such phenomenon are understood.

\section{Conclusions}

The system implementation project initiated by the Department in 2002 was terminated in late 2009; most of the vendors were relieved, and all the participants moved on. The system cost the government a few millions, and thousands of person hours of effort. The committee that had been set up to examine the problems with the project did create a valuable report that included lessons on project management. The personnel who had participated in the project had gained from their experience. Barring the last two positive outcomes, overall the project was a failure.

The phenomenon of rituals examined in this paper is not easy to uncover and establish. A question that arises from this research is how rituals can be identified in projects? A related question is how the overtly rational actions can be delineated from those required for the success of the project? One answer to these questions may be found in the possible predictors of problems and project failure - creation of parallel structures of governance that undermines the existing hierarchy; conducting a requirements analysis without including important stakeholders; using an approach to systems development that is at odds with the familiar methods used in the organisation; and shifting project execution responsibility to those without a buy-in to the project.

The method followed in this research was that of interviewing participants during the course of the project, albiet towards the end. Interviews, of a crosssection of the stakeholders, about the goals and intentions of actions taken during the project, the meaning of certain practices of project management, and the conflicts that arose within the organisation, led to uncovering the rituals enacted. This method is a first attempt to understand rituals in e-government projects, and future work will address the deeper issues of interpretation of the interview data.

\section{References}

1. Anand, N., Watson, M.R.: Tournament rituals in the evolution of fields: The case of the grammy awards. The Academy of Management Journal 47(1), 59-80 (2004)

2. Barki, H., Hartwick, J.: Interpersonal conflict and its management in information system development. MIS Quarterly 25(2), 195-228 (2001)

3. Baronas, A.M.K., Louis, M.R.: Restoring a sense of control during implementation: How user involvement leads to system acceptance. MIS Quarterly 12(1), 111-124 (1988) 
4. Bell, C.: Ritual: Perspectives and Dimensions. Oxford University Press, Oxford (2009)

5. Bjerknes, G., Bratteteig, T.: User participation and democracy: A discussion of Scandinavian research on system development. Scandinavian Journal of Information Systems 7(1), 73-98 (1995)

6. Bostrom, R.B., Heinen, J.A.: MIS problems and failures. a socio-technical perspective: Part i: The causes. MIS Quarterly 1(3), 17-32 (1977)

7. Ginzberg, M.: Early diagnosis of MIS implementation failure: Promising results and unanswered questions. Management Science 27(4), 459-478 (1981)

8. Heeks, R.: Information systems and developing countries: Failure, success, and local improvisations. The Information Society 18, 101-112 (2002)

9. Heeks, R.: Most eGovernment-for-development projects fail: How can risks be reduced? iGovernment working paper series, IDPM, University of Manchester (2003)

10. Keil, M.: Pulling the plug: Software project management and the problem of project escalation. MIS Quarterly 19(4), 421-447 (1995)

11. Krishna, S., Walsham, G.: Implementing public information systems in developing countries: Learning from a success story. Information Technology for Development 11(2), 1-18 (2005)

12. Madon, S.: Evaluating the developmental impact of e-governance initiatives: An exploratory framework. The Electronic Journal of Information Systems in Developing Countries 20(5), 1-13 (2004)

13. Markus, M.L.: Power, politics, and MIS implementation. Communications of the ACM 26(6), 430-444 (1983)

14. Parthasarathy, B.: Information and communication technologies for development: A comparative analysis of impacts and costs from India. Tech. rep., International Institute of Information Technology, Bangalore (2005)

15. Prakash, A., De', R.: Importance of developement context in ICT4D projects: A study of computerization of land records in India. Information Technology \& People 20(3), 262-281 (2007)

16. Robey, D., Markus, M.L.: Rituals in information system design. MIS Quarterly $8(1), 5-15$ (1984)

17. Silva, L., Hirschheim, R.: Fighting against windmills: Strategic information systems and organizational deep structures. MIS Quarterly 31(2), 327-354 (2007)

18. Vanaik, A.: The Painful Transition: Bourgeois Democracy in India. Verso, New York (1990)

19. Yin, R.K.: Case Study Research: Design and Methods. Applied Social Science Research Methods Series, vol. 5. Sage Publications, Thousand Oaks (2003) 